\section{Is Trust Necessary to Increase Loyalty in Adult Consumers?}

Journal PSIKODIMENSIA

Volume 17, No. 2, Juli - Desember 2018

ISSN cetak : 1411-6073

ISSN online : $2579-6321$

DOI 10.24167/psidim.v17i2.1658

\begin{abstract}
Kinanti Alvani Pane; Martina Dwi Mustika; Bertina Sjabadhyni
Faculty of Psychology, Indonesia University

e-mail: martinadwimustika@gmail.com
\end{abstract}

\begin{abstract}
The aim of this study is to examine if brand experience can predict brand loyalty of older adult consumers through brand trust. This cross-sectional study involved 390 Indonesian older adult consumers of a mineral water who completed a self-report questionnaire. Mediation analysis suggested that brand experience was significant for predicting brand loyalty, either directly or indirectly, suggesting partial mediation. This result further implied that older adult consumers' experience of a brand can maintain ongoing brand loyalty.In addition, brand trust does not necessarily influence the relationship between brand experience and brand loyalty, which implies that experience is sufficient to maintain older adult consumers' loyalty to the product. The limitations of this research and potential future research is also discussed.
\end{abstract}

Keywords: Brand Experience, Brand Loyalty, Brand Trust, Older Adult Consumer.

\section{INTRODUCTION}

The population of older adults continues to growdue to increased life expectancy, which currently stands at 71.4 years (GHO, 2018). Healthy lifestyles and a lower birth rate are also contributing factors in the rising older adult population (Drolet, Schwarz \& Yoon, 2011; Moschis, 2012). In the future, older adults are likelyto outnumber youths.From an economic perspective, an increased number of older adults may have interesting implications for market segmentation. Unfortunately, so far marketers only view older adult consumers as a homogeneous market. There are few studies of older adult consumers (Moschis, 2012). This is evidenced by the lack of advertisement models, products and services specifically targeted to older adult consumers (Long, 1998). Meanwhile, the pattern of older adult consumption may also change due to life events such as the loss of loved ones, retirement, declining health conditions, slow understanding of technology and the need for assistance in some tasks (Berg, 2015; Moschis, 2012). Changes in consumption patterns of older adults has a tendency to lead to increased spending on matters relating to health, donations and gifts, rather than on items such as cars or on leisure or recreation (Hurd \&Rohwedder, 2011). Based on these factors, older adult consumers should be regarded as constituting a more heterogeneous market share and deserving of greater attention.

The number of Indonesian older adult consumers is likely to reach 80 million in 2050 (Haryanto, 2017). A considerable number of potential older adult consumers in the South-East Asian region is important for producers around 
the world to market their products in Indonesia. However, it is rare to find consumer behaviour research conducted in Indonesia. We believe that research on older adult consumers in Indonesia or South-East Asia should be developed and conducted to improve thetheoretical and practical understanding of their behaviours, perceptions and attitudes. In addition, this kind of research will promote further understanding of the differences and similarities between Western and Eastern consumers, particularly older adult consumers.

As a promising market segmentation, the loyalty of older adult consumers towards a product-often referred to as brand loyalty-warrants greater consideration by companies seeking to increase profit (Dekimpe, Steenkamp, Mellens \& Abeele, 1997). Oliver (1999) defines brand loyalty as a consumer commitment to repurchase products or services from the same brand, although there are situational influences that can lead to changes in consumer behaviour. Brand loyalty can be divided into two dimensions: behavioural or purchase loyalty and attitudinal loyalty (Chauduri \& Holbrook, 2001). Behavioural loyalty is the recurring purchase behaviour of a particular brand, while attitudinal loyalty is a consumers' commitment to making repeat purchases due to the unique values consumers associate with the brand (Chauduri \& Holbrook, 2001). Brand loyalty is often measured by the frequency of consumer purchases.However, a high frequency of purchases does not necessarily prove that consumers are loyal to a brand (Baloglu, 2002). It could be that the consumers made a purchase because they wanted the benefits offered by marketers through repeat purchases (Baloglu, 2002). The measurement of brand loyalty in this research is not measured only by the frequency of repeat purchases, but also by attitudinal attachment, which demonstrates customer commitment to a brand.

Loyal customers voluntarily provide recommendations to other consumers (Chauduri \& Holbrook, 2001). Thus, a company can acquire new customers with lower marketing costs and through customers not being easily tempted by the offerings of competitors (Baloglu, 2002). In collective culture, based on our experiences in Indonesian communities, it is common to hear older adults recommend certain products based on their personal preferences. It would be interesting to determine how older adults in collectivist culture perceive their loyalty towards a brand and their perceptions of the factors that underpin that loyalty. Aside from that, older adult consumers tend to repeatedly purchase a brand that has been available for a long time (Lambert-Paundraud, Laurent \&Lapersonne, 2005). As such, it would be less time consuming for them to search for information about the product or brand (Deshpande \& Krishnan, 1981).

Previous studies (mostly conducted in Western countries)have mentioned some antecedents of brand loyalty such as brand satisfaction, brand equity, brand value, brand trust (Kuikka\&Laukkanen, 2012), customer perceived ethicality (Singh, Iglesias \& Batista-Foguet, 2012) and brand experience (Iglesias, Singh \& BatistaFoguet, 2011). In this study, brand experience and brand trust are explored to determine their effect on the brand loyalty of older adult consumers in Indonesia.

Brand experience is a recent concern of some researchers because consumers no longer purchase only products and services; they also buy the experiential elements of those products (Morrison \& Crane, 2007). Brand experience is an internal response 
(sensation, feeling and cognition) and consumer behavior is generated by the stimuli of a brand of design, identity, packaging, communication and environment (Brakus, Scmitt \& Zarantonello, 2009). Consumer brand experience refers to consumers' knowledge and familiarity with the brand (Alba \& Hutchinson, 1987; Ha \& Perks, 2005). Brand experience is divided into two elements: direct and indirect experience (Ha \& Perks, 2005). Direct experience is the interaction of consumers with elements such as the actualproduct and customer service.Indirect experience is the interaction of consumers with third parties. Consumers are said to feel and receive brand experience when they assess, not only the attributes and benefits of the product, but also the experience gained when using it (Schmitt \& Rogers, 2008). Real and clear experience with a brand has a greater effect than the features and advantages of the product because it will be recorded clearly in consumers' memory (Ha \& Perks, 2005). Older adult consumers in collectivist culture are more likely to gain brand experience indirectly; that is, from interaction with third parties, since they are more likely to belong to a group in their society (Triandis, Bontempo, Villareal, Asai \& Lucca, 1988).

Previous research has discovered a positive relationship between brand experience and brand loyalty (Brakus et al., 2009; Iglesias et al., 2011; Nysveen, Pedersen \& Skard, 2013; Ramaseshan \& Stein, 2014; Şahin, Zehir \& Kitapçi, 2011). However, research conducted by Iglesias et al. (2011) on 195 students at business schools in Spain stated that the relationship between brand experience and brand loyalty will only be significant if mediated by effective commitment. However, we argue that brand trust is more likely to influence the relationship between brand experience and brand loyalty.

Brand trust is the willingness of a consumer to have faith in the function of a brand.It is the key to a long-term relationship between consumers and products (Chauduri \& Holbrook, 2001; Morgan \& Hunt, 1994). Previous research has indicated a positive relationship between brand trust and brand loyalty (Matzler, Grabner-Kräuter \& Bidmon, 2008; Sahin et al., 2011) and between brand trust and brand experience (Ha \& Perks, 2005; Sahin et al., 2011). We argue that if consumers have trust in a brand, they tend to more easily develop a positive attitude towards the product in the future (Lau \&Lee, 1999). Further, the growth and development of brand trust in older adult consumers is important in view of the risky situation that this demographic can face when choosing a brand that includes matters of health and safety. We assume that the effects of brand experience on brand loyalty will increase when consumers have brand trust. Trust is the key to any relationship (Morgan \& Hunt, 1994) and will lead to brand loyalty (Chauduri \& Holbrook, 2001). Therefore, a positive brand experience will generate brand trust in situations in which brand trust can be a mediator in the relationship between brand experience and brand loyalty. In light of this, we have developed a hypothesis (see Figure 1): brand trust positively influences the relationship between brand experience and brand loyalty. 


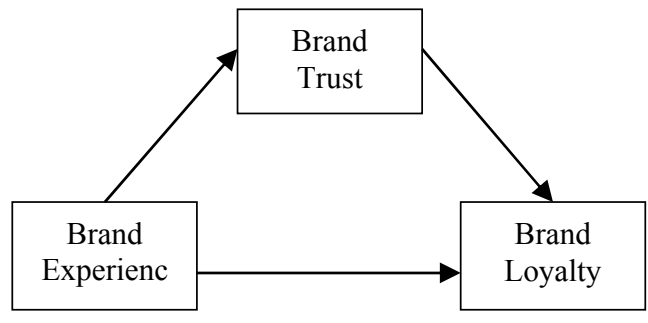

Figure 1: Hypothesised model of brand experience and brand loyalty.

\section{METHOD}

This study involved 390 older adult Indonesian consumers $\left(M_{\mathrm{Age}}=\right.$ 64.50 ,

$\left.S D_{\text {Age }}=6.62\right)$ who were members of older adult communities and groups in Indonesia. All respondents had a minimum age of 56 years and were consumers of a bottled water brand. Life expectancy of Indonesians remains between 67 years (male) and 71 years (female).The retirement age of employees is 55 years (Central Bureau of Statistics, 2014; Government Regulation No. 21 of 2014). Therefore, we determined the age limit of respondents in this study to be 56 years and over. In addition, all respondents had to be able to participate in, and make, buying decisions and do their shopping themselves. A brief description of the study was given to all respondents and their participation in the study indicated consent. All respondents received a gift for their participation.

A well-known brand of bottled water in Indonesia was used in this study.The name of the brand was omitted for confidentiality. We used this brand because we believedour participants were familiarwith this water. We asked about a slogan used in the brand advertisements to control whether participants already knew the product. We only used data from participants who answered the question correctly.
We used items from Chaudhuri and Holbrook's (2001) study to measure both brand loyalty and brand trust. There were four items to measure brand loyalty and four items to measure brand trust. The items for brand loyalty included 'I intend to keep purchasing this brand' and 'I am committed to this brand'. The items for brand trust were 'I trust this brand', 'I rely on this brand', 'this is an honest brand' and 'this brand is safe'.

Brand experience was measured using a five-item adapted version of $\mathrm{Ha}$ and Perks's (2009) questionnaire. Items included 'I often like to participate in the community of the product', 'I participate in a special event offered by the product' and 'offering reasonable prices is very important for the product'. We adapted all items to suit the product under study.

A seven-point Likert-style scale was used for scoring for all items, ranging from one(strongly disagree) to seven (strongly agree). Cronbach's alpha of all measures from previous studies was reported as between 0.810.90 , which showed good reliability.

All measures were translated into Bahasa Indonesian using translation procedures from Sousa and Rojjanasrirat (2011). We also conducted a pilot test before the questionnaires were given to potential respondents and made several corrections to improve the meaning and understanding of each statement based on the results. The reliability results (Cronbach's alpha) for Bahasa Indonesia ranged from 0.81-0.89, which was similar to the original version in English.

We used mediation analysis using process macro for IBM SPSS Version 22 (Hayes, 2013). All scores were centred to reduce collinearity (Dawson, 2014). We also tested the mediation using a bootstrap estimation approach 
Kinanti Alvani Pane: Is Trust Necessary to Increase Loyalty ...

with 5,000 samples (Hayes, 2013). The datasets generated and analysed in the study are available from the corresponding author on reasonable request.

\section{RESULT}

The means, standard deviations and correlation results are presented in Table 1. The correlation between brand experience and brand trust and between brand experience and brand loyalty were positive and moderately correlated. The relationship between brand trust and brand loyalty showed a high correlation. All scales had a satisfactory reliability score and (Cronbach's alpha) ranged between $\alpha=0.81$ and $\alpha=0.89$. Table 2 presents the coefficient of the model.

\section{Table 1.}

Means, Standard Deviations, Correlations and Scale Reliabilities

\begin{tabular}{llllll}
\hline & Mean & SD & BE & BT & BL \\
\hline BE & 22.68 & 3.75 & .814 & & \\
BT & 19.00 & 3.39 & $.699^{* *}$ & .851 & \\
BL & 18.69 & 3.68 & $.653^{* *}$ & $.822^{* *}$ & $\mathbf{. 8 8 9}$ \\
\hline
\end{tabular}

Note. Diagonal entries in bold are scale reliabilities (Cronbach alpha).

$\mathrm{BE}=$ brand experience; $\mathrm{BT}=$ brand trust; and $\mathrm{BL}=$ brand loyalty.

*. Correlation is significant at the 0.05 level (2-tailed).

**. Correlation is significant at the 0.01 level (2-tailed).

The results suggested that brand experience predicted brand trust $(\beta=$ $.632, S E=.034, t=18.629, p=.000$, LLCI $=.566$, ULCI $=.698)$ and brand trust predicted brand loyalty $(\beta=.776$, $S E=.047, t=16.473, p=.000$, LLCI $=$ .684 , ULCI $=.869$ ). Brand experience remained a predictor of brand loyalty after brand trust was considered, although the effect of the relationship was lower $(\beta=.151, S E=.041, t=$ $3.682, p=.003$, LLCI $=.703$,
ULCI $=.231)$, with a 69 per cent variance in brand loyalty $\left(\mathrm{R}^{2}=.688\right)$. The result of indirect effect was significant $(\beta=\quad$.490, $S E=.037$, LLCI $=.421$, ULCI $=.565$ ). Further Sobel tests also showed a significant indirect effect $(\beta=.490$, $S E=.040, z=12.331, p=.000)$. Therefore, the results suggested that brand experience indirectly predicted brand loyalty through brand trust and showed a partial mediation.

Table 2.

\section{Mediation Analysis Result}

\begin{tabular}{|c|c|c|c|c|c|c|c|c|}
\hline \multirow{3}{*}{ Antecedent } & \multicolumn{8}{|c|}{ Consequent } \\
\hline & \multicolumn{4}{|c|}{ Brand Trust } & \multicolumn{4}{|c|}{ Brand Loyalty } \\
\hline & $\beta$ & $S E$ & $t$ & $p$ & $\beta$ & $S E$ & $t$ & $p$ \\
\hline \multirow{4}{*}{$\begin{array}{l}\text { Constant } \\
\text { BE } \\
\text { BT }\end{array}$} & 4.672 & 0.754 & 5.885 & 0.000 & 0.525 & 0.708 & \multirow{3}{*}{$\begin{array}{l}0.742 \\
3.682 \\
16.473\end{array}$} & 0.458 \\
\hline & 0.632 & 0.034 & 18.629 & 0.000 & 0.151 & 0.041 & & 0.003 \\
\hline & - & - & & - & 0.776 & 0.047 & & 0.000 \\
\hline & \multicolumn{4}{|c|}{$\begin{array}{l}\mathrm{R}^{2}=0.489 \\
\mathrm{~F}(1,388)=347.049 \\
\mathrm{p}=0.000\end{array}$} & \multicolumn{3}{|c|}{$\begin{array}{l}\mathrm{R}^{2}=0.688 \\
\mathrm{~F}(2,387)=398.637 \\
\mathrm{p}=0.000\end{array}$} & \\
\hline
\end{tabular}

$\mathrm{BE}=$ brand experience; $\mathrm{BT}=$ brand trust $;$ and $\mathrm{BL}=$ brand loyalty. 



\section{DISCUSSION}

This study investigated the role of brand trust in influencing the relationship between brand experience and brand loyalty. We argued that older adult consumers' brand experience predicted their loyalty through their trust towards a product. The hypothesis was tested using mediation analysis and the result suggested a partial mediation because the relationship between brand experience and brand loyalty remained significant when brand trust was considered. These findings meant that older adult consumers still had loyalty to the product eventhough they did not entirely trust the product. Thus, trust in older adult consumers is only likely to slightly improve brand loyalty.

Our findings were consistent with Şahin et al.'s study (2011) that brand trust plays a partial role in the relationship between brand experience and brand loyalty. It can be explained using the social exchange theory, which states that parties treated well by others tend to be obliged to reciprocate with good treatment (Blau, 1964). When a brand can provide a positive experience and is in accordance with the promise held out to consumers, consumer brand trust is likely to increase. Consumers tend to respond positively when they possess brand loyalty. In our study, older adult consumers who had a positive brand experience of the bottled water brand were more likely to desire a repeat positive experience. This positive experience can create an emotional bond between consumers and brands, leading to increased brand loyalty (Gentile, Spiller\&Noci, 2007). Consumers who have brand loyalty will tend to recommend the brand to other consumers (Chauduri\&Holbrook, 2001).

In addition, this study was conducted in a collectivist society, which places emphasis on the social framework in which one expects others to be part of the group to safeguard and protect oneself (Triandis et al., 1988). A collective society demonstrates high attachment and group togetherness. Shared experiences of older adults (e.g., in prayer groups) in one environment can affect their behaviours (Moschis, 2012). When one member has a positive experience with a brand, they share their positive experiences with their friends. They may invite other members of the group to use the brand voluntarily so that others may have similar positive experiences. This may then increase the likelihood of brand experience in predicting brand loyalty directly.Moreover, 80 per cent of older adult respondents were still responsible for their own shopping. We assumed that when older adult consumers shop alone, they assess and have a real and direct experience with the product. Thus, the higher the elderly consumers' trust in a brand, the higher the brand experience prediction of brand loyalty.

\section{CONCLUSION}

In conclusion, this study has further elaborated on, and supported, previous research on older adult consumer studies in Indonesia. The mediation analysis suggested that older adult consumers who had a positive brand experience towards the product tended to have loyalty towards the product, even when they did not trust the product. The findings suggested that marketers are expected to provide a unique and unforgettable brand experience for older adult customers. This would encourage older consumers to continue to buy the product in the future.

The practical implications for this study are for markerters who want to sell their product in a collectivist society. They should consider providing more user experiences in their marketing strategies. This would hopefully result in positive stories about the product being 
spread in local communities, leading to more people using the product.

This study demonstratedthe importance of evidence in older adult consumers' studies in Indonesia, one of SouthEast Asian countries. The results of this study shared similarities to the results of previous studies; however, the respondents in this study were older adult consumers. The findings in this study support the statement of Moschis (2012) that many theories of older adult consumers suggest that their behaviour tends to be homogeneous. However, one must consider that this study focused on only one type of product, which was purely utilitarian. Hurd and Rohwedder (2011) stated that changes in the pattern of older adult consumers' consumption causes them to spend more money on items that have elements of vacations or recreations. As such, it is necessary to conduct further research with other types of products to fully understand the diversity of consumption patterns of older adult consumers.

Our study was limited by the use of a single utilitarian product. The result of the study would perhaps have been more interesting if both utilitarian and hedonic products were used. We also suggest conducting research on companies that have direct engagement with consumers so that consumers can experience a real-life and direct experience. Another limitation is that our study was based on a self-report questionnaire and the data wereanalysed using a correlational analysis. Future research could have more meaningful results if conducted using an experiment method, allowing for a more comprehensive exploration of the relationship between variables (Gravetter\&Forzano, 2012). Further research comparing several products may also increase our understanding of older adult consumers'behaviour, particularly in Asian countries.
Therefore, comparing results between two or several countries is important.

\section{REFERENCES}

Alba, J. W.\&Hutchinson, J. W. (1987). Dimensions of consumer expertise. Journal of Consumer Research,13(1), 411-454.

Baloglu, S. (2002). Dimensions of customer loyalty: Separating friends from well wishers.Cornell Hotel and Restaurant Administration Quarterly,43(1), 47-59.

Berg, L. (2015). Consumer vulnerability: Are older people more vulnerable as consumers than others? International Journal of Consumer Studies,39(4), 284293.

Blau, P. M. (1964). Exchange and power in social life. New York: Academic Press.

Brakus, B., Scmitt, B. H.and Zarantonello, L. (2009). Brand eperience: What is it? How is it measured? Does it affect loyalty? Journal of Marketing, 73(3), 5268.

Chaudhuri, A. \& Holbrook, M.B. (2001). The chain of effects from brand trust and brand affect to brand performance: The role of brand loyalty.Journal of Marketing,65, 81-93.

Dawson, J.F. (2014). Moderation in management research: What, why, when, and how. Journal of Business and Psychology,29(1), 1-19. 
Dekimpe, M., Steenkamp, J-B., Mellens, M.\&Abeele, P. (1997). Decline and variability in brand loyalty.International Journal of Research in Marketing,14(5), 405-420.

Deshpande, R. \&Krishnan, S. (1981). Correlates of deficient consumer information environments: The case of the elderly. Advances in Consumer Research,9, 515-519.

Drolet, A., Schwarz, N.\&Yoon, C. (2010). The aging consumer: Perspectives from psychology and economics. New York: Routledge.

Gentile, C., Spiller, N. \&Noci, G. (2007). How to sustain the customer experience: An overview of experience components that co-create value with the customer. European Management Journal,25(5), 395410.

Global Health Observatory (GHO). (2018)Life expectancy. Retrieved from

http://www.who.int/gho/mortality burden_disease/life_tables/situat ion_trends/en/.

Gravetter, F. J. \&Forzano, L. A. B.(2012). Research methods for the behavioral sciences (4thed.). Canada: Wadsworth Cengage Learning.

Ha, Y.H. \&Perks, H. (2005). Effects of consumer perceptions of brand experience on the web: Brand familiarity, satisfaction and brand trust. Journal of Consumer Behaviour,4(6), 438-452.

Haryanto, J. T. (2017). Penduduklansiadan bonus demografikedua (Elderly population and second demographic bonus). Retrieved from

KementerianKeuanganRepublik
Indonesia webpage: https://www.kemenkeu.go.id/publ ikasi/artikel-dan-opini/penduduklansia-dan-bonus-demografikedua/.

Hayes, A. F. (2013). Introduction to mediation, moderation, and conditional process analysis: A regression-based approach. New York: The Guildford Press.

Hurd, M. \&Rohwedder, S. (2011). Effect of the economic crisis on the older population: How expectations, consumption, bequests, and retirement responded to market shocks (PRC WP2011-09). Philadelphia: Pension Research Council.

Iglesias, O., Singh, J. J.\&Batista-Foguet, J. M. (2011). The role of brand experience and affective commitment in determining brand loyalty. Journal of Brand Management, 18(8), 570-582.

Kuikka, A.\&Laukkanen, T. (2012). Brand loyalty and the role of hedonic value. Journal of Product \& Brand Management, 21(7), 529-537.

Lambert-Paundraud, R., Laurent, G.\&Lapersonne, E. (2005). Repeat purchasing of new automobiles by older consumers: Empirical evidence and interpretations. Jornal of Marketing,69, 97-103.

Lau, G.T. \&Lee, S.H. (1999). Consumers' trust in a brand and the link to brand loyalty.Journal of Market Focused Management,4, 341-370.

Long, N. (1998). Broken down by age and sex: Exploring the ways we approach the older adult consumer.Journal of the Market Research Society,40(2), 73-91. 
Matzler, K., Grabner Kräuter, S.\&Bidmon, S. (2008). Risk aversion and brand loyalty: The mediating role of brand trust and brand affect. Journal of Product \& Brand Management,17(3), 154-162.

Morgan, R. M. \&Hunt, S. D. (1994). The commitment-trust theory of relationship marketing. Journal of Marketing,58, 20-38.

Morrison, S.\&Crane, F. G. (2007). Building the service brand by creating and managing an emotional brand experience.Journal of Brand Management,14(5), 410-421.

Moschis, G. P. (2012). Consumer behavior in later life: Multidisciplinary approaches and methodological issues.Research in Consumer Behavior,9, 103128.

Nysveen, H.,Pedersen, P.\&Skard, S. (2013). Brand experiences in service organizations: Exploring the individual effects of brand experience dimensions. Journal of Brand Management,20(5), 404423.

Oliver, R. L. (1999). Whence consumer loyalty?Journal Marketing,63,33-44.

of

Ramaseshan, R.\&Stein, A. (2014). Connecting the dots between brand experience and brand loyalty: The mediating role of brand personality and brand relationships.Journal of Brand Management, 2, 664-683.

Şahin, A.,Zehir,C.\&Kitapçi, H. (2011). The effects of brand experiences, trust and satisfaction on building brand loyalty: An empirical research on global brands.Procedia-Social and
Behavioral Sciences,24, 12881301.

Schmitt, B. H.\&Rogers, D. L. (2008). Preface. In: B.H. Schmitt and D.L. Rogers (eds.)Handbook on brand and experience management(pp. $\quad \mathrm{ix}-\mathrm{x}$ ). Cheltenham, UK: Edward Elgar.

Singh, J. J., Iglesias, O.\&Batista-Foguet, J. M. (2012). Does having an ethical brand matter? The influence of consumer perceived ethicality on trust, affect and loyalty.Journal of Business Ethics,111(4), 541-549.

Sousa, V. D. \&Rojjanasrirat, W. (2011). Translation, adaptation and validation of instruments or scales for use in cross cultural health care research: A clear and user friendly guideline. Journal of Evaluation in Clinical Practice, 17(2), 268-274.

Triandis, C.H., Bontempo, R., Villareal, M.J., Asai, M. \&Lucca, N. (1988). Individualism and collectivism: Cross-cultural perspectives on self-ingroup relationships. Journal of Personality and Social Psychology,54(2), 323-338. 